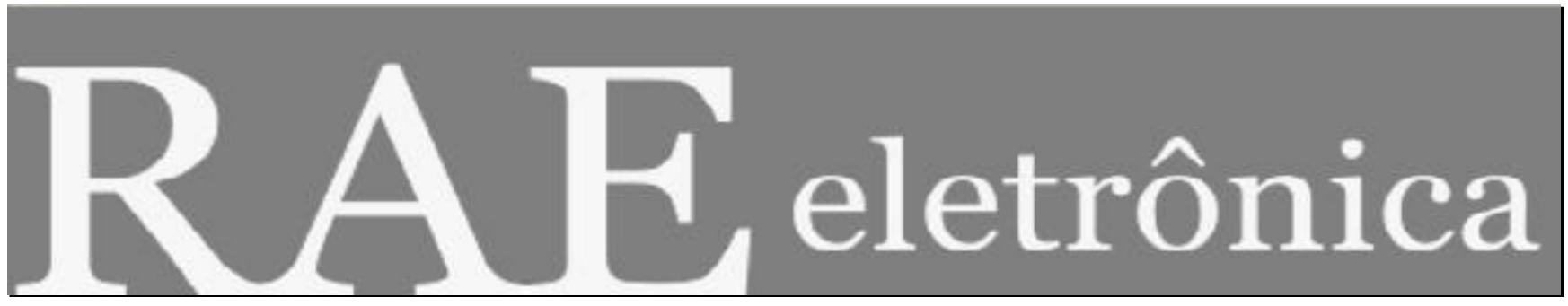

\title{
É POSSÍVEL INOVAR EM MANUAIS DE TEORIA ORGANIZACIONAL?
}

Por:

Isabela Baleeiro Curado, FGV-EAESP

RAE-eletrônica, v. 5, n. 1, Resenha 2, jan./jun. 2006

http://www.rae.com.br/eletronica/index.cfm?FuseAction=Artigo\&ID=4163\&Secao=RESENHAS \&Vol ume $=5 \&$ Numero $=1 \&$ Ano $=2006$

CCopyright, 2006, RAE-eletrônica. Todos os direitos, inclusive de tradução, são reservados. É permitido citar parte de artigos sem autorização prévia desde que seja identificada a fonte. A reprodução total de artigos é proibida. Os artigos só devem ser usados para uso pessoal e nãocomercial. Em caso de dúvidas, consulte a redação: raeredacao@fgvsp.br.

A RAE-eletrônica é a revista on-line da FGV-EAESP, totalmente aberta e criada com o objetivo de agilizar a veiculação de trabalhos inéditos. Lançada em janeiro de 2002, com perfil acadêmico, é dedicada a professores, pesquisadores e estudantes. Para mais informações consulte o site www.rae.com.br/eletronica.

RAE-eletrônica ISSN 1676-5648

(O2006 Fundação Getulio Vargas - Escola de Administração de Empresas de São Paulo.

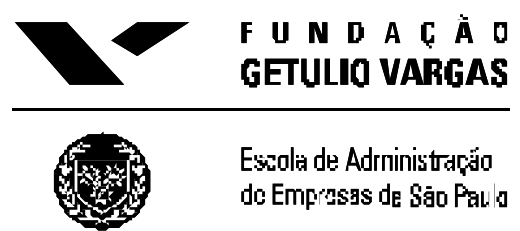




\section{É POSSÍVEL INOVAR EM MANUAIS DE TEORIA ORGANIZACIONAL?}

Por :

Isabela Baleeiro Curado

Professora da FGV-EAESP

E-mail: icurado@fgvsp.br

\section{MANAGING AND ORGANIZATIONS: AN INTRODUCTION TO THEORY AND PRACTICE}

De Stewart Clegg, Martin Kornberger e Tyrone Pitsis

London: Sage Publications, 2005. 584 p.

A área de teoria organizacional está repleta de manuais, utilizados nas universidades americanas, principalmente nos cursos de Organizational Behavior. Esses manuais geralmente seguem a mesma lógica: uma introdução com um apanhado geral da história da Administração; alguns capítulos sobre o ambiente externo da organização (forças ambientais, stakeholders, ética e responsabilidade social); uma parte sobre planejamento (incluindo tomada de decisão); uma parte sobre organização (estrutura, administração de recursos humanos, cultura e mudança); outra parte que aborda a dimensão da liderança (motivação, trabalho em equipe, comunicação); e, finalmente, uma parte sobre controle. Uma das características principais desses manuais é adotar uma abordagem funcionalista.

Pode-se observar, na última década, a publicação de manuais de teoria das organizações com abordagens alternativas como, por exemplo, o pioneiro Imagens das Organizações, de Gareth Morgan; o Organizing \& Organizations, de Gabriel, Fineman e Sims; o Handbook de Estudos Organizacionais, organizado por Clegg, Hardy e Nord; e o Organizational Theory, de Hatch. O manual publicado por Clegg, Kornberger e Pitsis, Managing and Organizations, pode ser classificado no grupo de manuais que buscam apresentar uma abordagem alternativa.

A proposta dos autores é apresentar uma nova abordagem ao processo de gestão por meio de um texto reflexivo, equilibrando o que o leitor precisa saber e aquilo que ele gostaria de saber. Para tanto, estruturaram os capítulos e o conteúdo oferecendo tanto a abordagem funcionalista quanto a abordagem crítica.

Todos os capítulos, seguindo a lógica de um manual, apresentam nove itens: 1) o título do capítulo e os objetivos de aprendizagem; 2) Outline of the Chapter, ou a apresentação do capítulo; 3) 
Setting the Scene, o contexto em que se insere o tema do capítulo; 4) Central Approaches and Main Theories, as principais abordagens e teorias relacionadas ao tema; 5) Critical Issues, questões críticas, que visam questionar a abordagem funcionalista dominante, apresentada na seção anterior; 6) The Fine Print, numa alusão às letras pequenas que explicam os perigos potenciais de um produto, essa sessão visa apresentar o conhecimento tácito que as abordagens dominantes utilizam sem crítica; 7) Summary and Review, resumo do capítulo; 8) One More Time... apresenta um exercício; e, finalmente, 9) Additional Resources, que apresenta leituras, filmes e outros recursos de apoio.

A obra está dividida em três partes: Making Sense of Management, onde é apresentada a história e o campo da Administração; Managing Organizations, que aborda o presente e o cotidiano das e nas organizações; e Managing Change, que enfatiza os desenvolvimentos futuros e o processo de mudança organizacional. A primeira parte é subdividida em três capítulos. O objetivo principal do primeiro capítulo, Making Sense of Management, é entender a origem da Administração moderna. Para tanto, os autores apresentam a história da Administração e as idéias dos principais teóricos (Taylor, Fayol, Mayo, Follett, para citar alguns). No segundo capítulo, Managing Rationalities, aborda as diferentes racionalidades que influenciam o pensamento administrativo, principalmente a racionalidade burocrática (Weber). O terceiro capítulo, Managing Realities, aborda teorias contemporâneas que questionam o modelo burocrático.

A segunda parte do livro, Managing Organizations, apresenta alguns capítulos tradicionais dos manuais: como gerenciar desenho, poder, comportamento, liderança, cultura e comunicação. A diferença está no conteúdo e, em alguns momentos, na sua falta. O capítulo de desenho organizacional apresenta diversas teorias contingencialistas - como as de Burns e Stalker, Woodward, Aston Project e Mintzberg - para explicar o ajuste entre ambiente e desenho, sem apresentar os diferentes tipos de estrututura. O capítulo de poder e política aborda como as organizações cumprem seus acordos por meio das dimensões institucionais e estruturais das relações de poder, porém, na parte crítica, falta uma abordagem sociológica - como Foucault - ou uma análise psicanalítica. O capítulo de comportamento organizacional apresenta uma abordagem interessantes sobre valores universais (Schwartz) e várias abordagens sobre teorias de personalidade - traços, sociocognitiva, psicoanalítica e humanista - e a influência destes no comportamento organizacional. No capítulo de liderança são apresentadas as teorias tradicionais de liderança, além das abordagens mais recentes, como a teoria transacional, transformacional e carismática. Na discussão sobre cultura são apresentados, como teoria dominante os níveis de cultura (Schein), a discussão sobre homogeneidade cultural (Hofsteade) e culturas fortes (Peter e Waterman) e, na abordagem crítica, as perspectivas de diferenciação, integração e 
fragmentação. O capítulo sobre comunicação aborda os níveis de comunicação - didática, pequenos grupos, organizacional e de massa - e explora a comunicação organizacional.

A terceira parte do livro, Managing Change, propõe analisar os desafios que as organizações enfrentam atualmente, quais sejam, gerenciar conhecimento e aprendizage m, inovação e mudança, estratégia e globalização. O capítulo sobre conhecimento e aprendizagem aborda as diferentes fontes e os diferentes tipos de conhecimento, o processo de aprendizagem organizacional, os processos de colaboração e as comunidades de prática como forma de conhecimento e aprendizagem. A discussão sobre inovação e mudança aborda a mudança planejada (como em Lewin, Hammer e Champy) e a mudança processual (Pettigrew) e a relação entre inovação e caos (Pascale, Weick), e apresenta as questões políticas, relacionais e mercadológicas dos processos de inovação e mudança. O capítulo de estratégia apresenta as diferentes escolas (como Chandler, planejamento estratégico, desenho, posicionamento), o processo de construção de cenários estratégicos, a abordagem de competências e o conceito de estratégias emergentes. Finalmente, no capítulo sobre globalização são abordados os principais desafios que as empresas precisam adotar ao assumir uma postura de pensar globalmente e agir localmente, analisando os fluxos globais de dinheiro, pessoas, conhecimento e política.

O ponto forte do livro é a relação entre as abordagens dominantes e a abordagem crítica, apresentada de forma didática. Em todos os capítulos são apresentadas diversas imagens e, no subtítulo destas, comentários relacionados ao tema abordado no capítulo e perguntas provocadoras. A seção de recursos adicionais, apresentada no final de cada capítulo tem dicas muito úteis sobre filmes, livros e músicas que podem ser utilizados para melhor entender o processo de gerenciamento das organizações ou as teorias abordadas. Outro recurso muito interessante é o sítio do livro (www.ckmanagement.net), que oferece casos, links, vídeos e exercícios.

Com origens diferentes - Clegg é inglês, Kornberger, austríaco e Pitsis, australiano - os três autores são professores e pesquisadores de instituições de ensino australianas. Isso faz com que o manual apresente vários exemplos da realidade organizacional desse país, o que, para o meio acadêmico australiano, é uma grande vantagem. Para leitores de outros países, alguns exemplos apresentados estão muito distantes dos exemplos administrativos mais conhecidos.

A análise de um manual nos traz sempre a questão se dá para adotá-lo nos cursos que ministramos e, caso seja possível sua adoção, em quais cursos. O manual pode ser utilizado num curso de gestão, tanto para alunos de graduação quanto de pós-graduação lato sensu. Para as disciplinas mais tradicionais dos cursos de graduação em Administração o conteúdo apresentado é incompleto. Para as disciplinas introdutórias dos programas de pós-graduação lato sensu o conteúdo está mais adequado. 
Independente da adoção ou não, é um ótimo livro de referência, por apresentar os mesmos temas de sempre de uma forma diferente. 